\title{
COST OF PATIENT FOLLOW-UP AFTER POTENTIALLY CURATIVE LUNG CANCER TREATMENT
}

Katherine S. Virgo, $\mathrm{PhD}^{\mathrm{a}, \mathrm{b}}$

Keith S. Naunheim, $\mathrm{MD}^{\mathrm{a}, \mathrm{b}}$

Lowell W. McKirgan, $\mathrm{MA}^{\mathrm{b}}$

Mary Ellen Kissling, $\mathrm{BA}^{\mathrm{b}}$

John C. Lin, BS ${ }^{\text {a }}$

Frank E. Johnson, MD ${ }^{a, b}$
The two objectives of this study were to determine the range of recommended follow-up strategies for patients with lung cancer treated with curative intent and to estimate the cost of such follow-up. Ten articles delineating eight specific follow-up strategies were identified from a Medline search of the literature for 1980 through 1995 . An economic analysis was done of the costs associated with the identified strategies. Charge data obtained from the Part B Medicare Annual Data file and the Hospital Outpatient Bill file were used as a proxy for cost. Follow-up intensity varied widely across strategies for $\mathbf{5}$ years of posttreatment follow-up. Medicareallowed charges for 5-year follow-up ranged from a low of $\$ 946$ to a high of $\$ 5645$. When Medicare-allowed charges were converted to a proxy for actual charges by a conversion ratio of 1.62 , the range was $\$ 1533$ to $\$ 9145$, a fivefold difference in charges. There was no indication that more intensive, higher-cost strategies increased survival or quality of life. The published literature, including textbooks, holds few answers in this area. ( $J$ Thorac Cardiovase Surg 1996;112:356-63)
Eollow-up of patients with cancer has been a Frequently overlooked research topic with no widely accepted practice guidelines, weak attempts at measuring costs, and the potential for unrestrained costs. ${ }^{1}$ Among the estimated 180,000 new cases of primary lung cancer projected to be diagnosed in the United States this year, approximately 35,000 patients are treated with curative intent and enter follow-up programs. ${ }^{2,3}$ Approximately $30 \%$, $65 \%$, and $80 \%$, respectively, of patients undergoing resection because of TNM stage I, II, and III cancers will have recurrence within 5 years. ${ }^{4-6}$ Few of these recurrences are curatively treated. Second primary cancers will develop in approximately $2 \%$ to $3 \%$ of the

From the Department of Surgery, ${ }^{a}$ St. Louis University Health Sciences Center, and Surgical Service, ${ }^{b}$ St. Louis Department of Veterans Affairs Medical Center, St. Louis, Mo.

Supported in part by a Veterans Administration Health Services Research and Development Investigator Initiated Research grant No. 91-074.2.

Received for publication Sept. 12, 1995; revisions requested Oct. 24, 1995; revisions received Nov. 16, 1995; accepted for publication Nov. 21, 1995.

The views expressed in this paper are those of the authors and should not be construed as reflecting the official position of the Department of Veterans Affairs or St. Louis University.

Address for reprints: Katherine S. Virgo, PhD, Health Services Research, Department of Surgery, St. Louss University Health Sciences Center, 3635 Vista Ave., P.O. Box 15250, St. Louis, MO 63110-0250.

12/1/70792 same 35,000 patients each year (many of which are new lung cancers), a risk that is relatively constant during at least the first 5 years after treatment. ${ }^{5,7,8}$ Only $40 \%$ to $70 \%$ of second primary lung cancers are treated with curative intent. 9,10

Follow-up regimens generally consist of some combination of office visits, chest roentgenography, complete blood cell counts (CBCs), liver function tests, sputum cytologic tests, bronchoscopy, computed tomography (CT) of the chest, CT of the head, bone scans, magnetic resonance imaging (MRI) of the chest, and MRI of the head. In the design of surveillance strategies, combining modalities has been recommended so that recurrences and second primary tumors are detected earlier with the goal of facilitating potentially curative treatment or providing appropriate palliation. No single modality is simultaneously sensitive, specific, safe, inexpensive, and convenient. Each is valuable for detecting specific types of lesions.

Chest roentgenography has remained the primary diagnostic follow-up modality for patients with lung cancer, despite the Cooperative Early Lung Cancer Detection Program findings, which failed to demonstrate a survival advantage for systematic primary lung cancer screening. ${ }^{11-13}$ The value of any test in detecting recurrence is unknown. Although chest CT and MRI frequently provide more precise anatomic depiction than chest roentgenography, both are also often nonspecific. ${ }^{14}$ 
Chest CT, though only moderately sensitive and specific, is considered the most accurate and costeffective modality for the evaluation of potential neoplasms identified on chest roentgenography and is also useful for staging. ${ }^{15,16}$ MRI of the chest, an alternative modality previously touted as being more accurate than CT, has not been proven superior to $\mathrm{CT}$ in staging primary bronchogenic cancer, and its utility in diagnosing recurrent cancer or new primary lung cancer is not known. ${ }^{17-19}$ Because of its high cost and limited accessibility, MRI is not used as frequently as $\mathrm{CT}^{20}$ For the detection of brain metastases, MRI and CT are similarly sensitive and specific, but the yield is low unless symptoms and signs of central nervous system metastases are present. $^{21,22}$

Positron emission tomography appears promising for the differentiation of benign from malignant solitary lung nodules, with a sensitivity of $97 \%$ and a specificity of $82 \%,{ }^{23}$ and has been useful in staging disease in individual patients. Its overall role in posttreatment surveillance is currently unknown.

As a follow-up test to detect recurrence after operation, whole-body gallium scan has generated some interest, with a sensitivity of $77 \%$ and a specificity of $59 \%$ in some series. ${ }^{24}$ Others have not been able to duplicate these results, however, and it is not in common use. ${ }^{20}$

According to the Cooperative Early Lung Cancer Detection Program study conducted at the Mayo Clinic, Johns Hopkins University, and the Memorial Sloan-Kettering Cancer Center, conventional sputum cytologic testing can detect only a small percentage of lung cancers and provides no additional benefit over regular chest roentgenography. ${ }^{11-13}$ Preliminary results from an ongoing study suggest that immunostaining of these specimens may lead to the earlier detection of second primary tumors, but at much higher cost. ${ }^{25}$ With the use of archived specimens from the National Cancer InstituteJohns Hopkins University study, ${ }^{11}$ Tockman and associates $^{26}$ demonstrated that two monoclonal antibodies against small cell and non-small-cell lung cancer $r^{27,28}$ could predict the later development of lung cancer up to 2 years earlier than conventional cytologic testing with a sensitivity of $91 \%$ and a specificity of $88 \%$. This approach must be considered experimental at present.

Repeated examinations with a flexible bronchoscope are not recommended for screening most patients, athough individual patients undoubtedly benefit. ${ }^{29}$ In addition, regular bronchoscopic studies are unpleasant and costly to the patient. Generally, bronchoscopic studies are reserved for the evaluation of disease in patients with symptoms, abnormal physical findings, or lesions on imaging tests. ${ }^{30,31}$ When brush biopsy, imprint cytologic testing, and forceps biopsy are used in conjunction with bronchoscopy, a sensitivity of $97.3 \%$ and a specificity of $100 \%$ can be achieved. ${ }^{32}$

Various surveillance programs have been advocated after curative treatment of many solid tumors (that is, breast and colon), but little has been written about postoperative surveillance for lung cancer. Naunheim and associates ${ }^{20}$ reviewed several widely respected textbooks of thoracic surgery ${ }^{33-36}$ and found that only one textbook lists the topic in the index ${ }^{36}$ athough it is briefly covered in Roth and colleagues. ${ }^{35}$ Another more recent textbook also addresses the issue. ${ }^{37}$ Unfortunately, very little of what has been advocated is supported by objective data. It appears likely that physicians simply adopt the surveillance regimen specific to their training program. Because there are few analyses of whether intensity of follow-up actually benefits patients, this practice is difficult to justify.

The majority of recent reports recommend from 10 to 14 office visits and one or fewer chest CTs during the initial 5 years of follow-up. ${ }^{5,20,37-43}$ However, for all other follow-up methods, the range of tests used and the frequency of testing vary widely. Two prospective studies have been conducted to date, but neither used a randomized controlled trial design to compare outcomes of varying intensities of follow-up. There is currently no persuasive evidence that intensive follow-up detects recurrences and second primary tumors earlier, promotes earlier treatment of such lesions, lengthens survival, or improves quality of life., 39

With disagreement over the appropriate frequency of follow-up and no solid data on which to base surveillance strategies, it is not surprising that few attempts have been made to ascertain the costs associated with follow-up of patients with lung cancer. Walsh and associates ${ }^{8}$ retrospectively measured institution-specific charges for follow-up of patients with lung cancer at a single large cancer center for three subgroups of patients: those without recurrence during follow-up $(n=223)$, those with palliatively treated recurrence $(n=95)$, and those with curatively treated recurrence $(n=40)$. Charges included follow-up visit and diagnostic test charges, as well as treatment charges. It is unclear whether drug costs were also factored into the analysis. 
Table I. Total visits, tests, and charges for initial 5 years of follow-up after treatment across various strategies

\begin{tabular}{|c|c|c|c|c|c|c|c|c|}
\hline \multirow[b]{2}{*}{ Source } & \multicolumn{8}{|c|}{ Total visits, tests, charges } \\
\hline & Office visit & $C B C$ & Chem 3 & $L F T$ & $C X R$ & Chest CT & Head $C T$ & Bone scan \\
\hline Williams, $1981^{43}$; Pairolero, $1984^{5}$ & 12 & 12 & 0 & 0 & 12 & 0 & 0 & 0 \\
\hline \multicolumn{9}{|l|}{ Beattie, $1982^{41}$} \\
\hline Original $\dagger$ & 10 & 0 & 0 & 4 & 10 & 0 & 0 & 0 \\
\hline Revised (personal communication, 1995) & 17 & 0 & 0 & 0 & 17 & 0 & 0 & 0 \\
\hline Ginsberg, $1989^{42}$; Martini, $1995^{37}$ & 14 & 0 & 0 & 0 & 14 & 0 & 0 & 0 \\
\hline In patients with squamous cell carcinoma & 14 & 0 & 0 & 0 & 14 & 0 & 0 & 0 \\
\hline Fischer, $1996^{38}$ & 22 & 11 & 11 & 0 & 22 & 0 & 0 & 0 \\
\hline Toporoff, $1995^{40}$ & 14 & 0 & 0 & 14 & 14 & 0 & 0 & 0 \\
\hline \multicolumn{9}{|l|}{ Virgo, $1995^{39} \div$} \\
\hline Intensive & 14 & 5 & 0 & 0 & 7 & 2 & 0 & 1 \\
\hline Nonintensive & 7 & 2 & 0 & 0 & 3 & 0 & 0 & 1 \\
\hline Walsh (in press) ${ }^{8}$ & 6 & 0 & 0 & 0 & 6 & 0 & 0 & 0 \\
\hline Naunheim (in press) ( $^{20}$ & 11 & 4 & 0 & 4 & 11 & 1 & 0 & 0 \\
\hline
\end{tabular}

Chem 3, Defined here as alkaline phosphatase, aspartate aminotransferase, and bilirubin; $L F T$, liver function test; $C X R$, chest roentgenography; $C E A$, carcinoembryonic antigen.

${ }^{*}$ Medicare charges times 1.62 conversion ratio.

$\dagger$ Only 2 years of follow-up listed under original strategy.

$\ddagger$ Actual patient follow-up during disease-free interval. No set follow-up protocol was imposed.

Average monthly charges were $\$ 365$ for patients without recurrence, $\$ 859$ for patients palliatively treated for recurrence, and $\$ 1256$ for patients curatively treated for recurrence. No attempt was made to apply nationwide charges to the surveillance data, although generalizability might have been improved had this been done.

In a similar, though much smaller study, Virgo and colleagues (unpublished manuscript) measured the charges for follow-up of patients with lung cancer at a single Veterans Affairs (VA) medical center during an 11-year period for two groups of patients: those followed up intensively $(n=120)$ and those followed up nonintensively $(n=62)$. Because the VA does not calculate charges for billing purposes, 1992 nationwide average Medicare-allowed charges ${ }^{44,45}$ were applied to retrospectively collected lung cancer follow-up data. Only surgical clinic visits and relevant diagnostic tests during the disease-free period were included in the cost analysis. For an average of 3 years of follow-up, Medicare-allowed charges totaled $\$ 477$ for patients followed up nonintensively and $\$ 2762$ for patients followed up intensively. Medicare-allowed charges were converted to a proxy for actual charges by a conversion ratio of 1.62, which the authors calculated from actual submitted charge data for $1992,44,45$ and this resulted in charges of $\$ 773$ for patients followed up nonintensively and $\$ 4475$ for patients followed up intensively.

A shortcoming in most analyses of follow-up of patients with lung cancer is the lack of cost or charge data. In response, the current study computes nationwide average charges associated with the follow-up of patients with lung cancer after treatment for eight separate follow-up strategies identified from the literature.

\section{Methods}

Follow-up strategies. A Medline search of the literature for 1980 to 1995 was done to identify citations that delineated specific surveillance strategies for patients undergoing curative resection because of primary lung cancer. Ten articles that depicted eight specific follow-up strategies for patients with lung cancer were identified (Table I).

Two reports outlined strategies for follow-up espoused by either medical societies or specific cancer centers. One was a handbook sponsored by the Connecticut State Medical Society in conjunction with other agencies, ${ }^{38}$ and the second represented the MD Anderson Cancer Center approach. ${ }^{40}$ Unfortunately, neither report presented specific outcome data such as time to detection of recurrence, curative second resections done, survival, or quality of life.

One study reported the mean follow-up strategy that resulted from a nationwide survey of all members of the Society of Thoracic Surgeons regarding current practice. ${ }^{20}$ This report documented wide variation among Society members regarding the frequency of and rationale for surveillance after operation. Though outcome data could not reliably be collected, physician motivation was addressed. Fewer than half of the respondents believed that surveillance resulted in survival benefit for patients with either TNM stage I or advanced-stage disease. The study detected other potential benefits such as increased rap- 


\begin{tabular}{|c|c|c|c|c|c|c|c|}
\hline \multicolumn{8}{|c|}{ Total visits, tests, charges } \\
\hline MRI of head & Bronchoscopy & Sputum cytology & $C E A$ & Urinalysis & Abdomen CT & Medicare charges & Actual charges* \\
\hline 0 & 0 & 12 & 0 & 12 & 0 & $\$ 2252$ & $\$ 3648$ \\
\hline 0 & 0 & 4 & 3 & 0 & 0 & $\$ 1777$ & $\$ 2878$ \\
\hline 0 & 0 & 0 & 0 & 0 & 0 & $\$ 2681$ & $\$ 4343$ \\
\hline 0 & 0 & 0 & 0 & 0 & 0 & $\$ 2208$ & $\$ 3576$ \\
\hline 0 & 0 & 14 & 0 & 0 & 0 & $\$ 2403$ & $\$ 3892$ \\
\hline 0 & 0 & 0 & 0 & 0 & 0 & $\$ 3695$ & $\$ 5986$ \\
\hline 0 & 0 & 0 & 0 & 0 & 0 & $\$ 2412$ & $\$ 3908$ \\
\hline 0 & 1 & 2 & 0 & 0 & 1 & $\$ 5645$ & $\$ 9145$ \\
\hline 0 & 0 & 0 & 0 & 0 & 0 & $\$ 1234$ & $\$ 2000$ \\
\hline 0 & 0 & 0 & 0 & 0 & 0 & $\$ 946$ & $\$ 1533$ \\
\hline 0 & 0 & 1 & 0 & 0 & 0 & $\$ 2583$ & $\$ 4185$ \\
\hline
\end{tabular}

port with primary care physicians and patients and avoidance of medicolegal conflicts.

One postoperative follow-up strategy was derived from two of the three thoracic surgery textbook references $^{36,37,42}$ (Shields $^{36}$ did not recommend a specific follow-up strategy). Ginsberg, Goldberg, and Waters ${ }^{42}$ and Martini and Ginsberg ${ }^{37}$ recommended essentially the same strategy, which is based on the yearly rate of recurrence after operation. They suggested that systematic, lifelong follow-up is crucial in the treatment of patients with lung cancer because only $30 \%$ to $40 \%$ will survive 5 years after operation without the development of recurrence and in some of these patients treatable second primary tumors will develop. Whether such strategies will affect long-term survival in the postresection at-risk population cannot be determined, because no outcome data were provided.

One strategy was extracted from a textbook devoted exclusively to the follow-up of the patient with cancer. ${ }^{41}$ One additional textbook on follow-up of the patient with cancer is currently in preparation, but was not available at the time of this review. ${ }^{46}$ Beattie $^{41}$ suggests that potential improvement in quality of life is a major reason for careful postoperative surveillance. Insufficient detail was provided to determine the data source that served as a basis for the suggested strategy of this author. Because the published article delineated a 2-year follow-up regimen only, the author was contacted to determine his strategy for years 3 through 5 after operation (Beattie, personal conversation, 1995). His strategy has changed somewhat since the time of the original article. For patients without symptoms, he currently recommends office visits and chest roentgenograms every 2 months in year 1 , every 3 months in years 2 through 3 , every 6 months in year 4 , and annually thereafter. He no longer recommends sputum cytologic tests, carcinoembryonic antigen tests, or liver function tests as originally recommended. For patients with advanced-stage disease, baseline brain and bone scans are also now recommended.

One strategy was derived from two articles that reported on different aspects of the same prospective study. The first article from this prospective study compared results in 350 patients enrolled in a regular follow-up program with results in 145 patients followed up less frequently. ${ }^{43} \mathrm{~A}$ major finding of this study was that survival did not differ significantly between the two groups, athough patients enrolled in a regular follow-up program did have higher survival probabilities at all intervals. The article did not report the average follow-up strategy among patients not in regular follow-up nor did it report time to detection of or the frequency of recurrences and second primary tumors. In addition, qualityof-life data were not collected.

Subsequent to that article, ${ }^{43}$ four of the original 350 patients were reported to have primary nonpulmonary neoplasms. The second article reported on only the remaining 346 patients with TNM stage I disease enrolled in a regular follow-up program. ${ }^{5}$ Overall survival was $69 \%$ at 5 years and $62 \%$ at 9 years. During the first 5 years of follow-up, rates of local recurrence, second primary tumors, and distant metastases averaged 1.86, 2.5, and 5.0 per 100 patient-years, respectively. Again, whether the same percentage of recurrent cancer cases would have been detected with less frequent follow-up cannot be determined and quality-of-life data were not collected. From neither of these articles can a determination be made of whether intensive follow-up detects recurrences and second primary tumors earlier, promotes earlier treatment of detected recurrences and second primary tumors, lengthens survival, or improves quality of life.

Two strategies represented the results of retrospective analyses of follow-up of patients with lung cancer at single facilities where no set follow-up protocol was prespecified. The first study retrospectively analyzed follow-up and outcomes among 358 patients undergoing lung resection at a large cancer center between 1987 and 1991. ${ }^{8}$ This article makes an important contribution to the literature, beyond the cost analysis mentioned earlier. Walsh and associates $^{8}$ discovered that only $9 \%$ (32 patients) of all patients followed up had recurrence diagnosed while they were still free of symptoms, of which only one third (10 patients) could be treated with curative intent. In other words, in only $3 \%$ of all patients did follow-up potentially 
make a difference in whether curative treatment was selected. As a result, the authors suggested a follow-up strategy that is less intensive than any other published strategy and concluded that follow-up for patients without symptoms is unlikely to be cost effective. The limitations of that study are the lack of quality-of-life data and the biases inherent in all retrospective research.

The second retrospective study analyzed follow-up and outcomes among 182 patients at a large midwestern VA hospital for the period 1982 to $1993 .{ }^{39}$ The authors found no significant difference in survival between patients followed up intensively and those followed up nonintensively, athough absolute survival differences between groups suggested that some benefit of intensive follow-up might exist. No patients were curatively treated for recurrence as a result of follow-up. Mean follow-up data for both the intensive and nonintensive strategies are presented here inasmuch as both represent actual practice patterns, athough the results suggested that nonintensive follow-up should be recommended. The limitations of the study of Walsh and associates ${ }^{8}$ apply to this study as well, in addition to sample size limitations. Both retrospective studies concluded that randomized prospective clinical trials are needed to definitively measure whether intensity of follow-up makes a difference.

Cost analyses. Nationwide average charges for 1992 associated with each of the eight follow-up strategies were computed and compared for a single patient with lung cancer followed up for 5 years. Charge data were obtained from the 1992 Part B Medicare Annual Data file ${ }^{44}$ and the first-quarter 1992 Hospital Outpatient Bill file. ${ }^{45}$ Average allowed charges nationwide for physician services were extracted from the Part B Medicare Annual Data file, which contains Medicare Part B data by current procedural terminology code and place of service, such as inpatient hospital, outpatient hospital, and office. With assistance from the Office of Research and Development of the Health Care Financing Administration, corresponding nationwide average facility charges were extracted from the Hospital Outpatient Bill file.

Physician charges and, where applicable, facility charges were summed to obtain a nationwide average charge per test or visit. A best-case scenario was assumed in calculating charges. For example, it was assumed patients were healthy and that additional workup on the basis of either symptoms or positive test results was not required. Further, it was assumed that each patient survived for 5 years, because the purpose of the analysis was to measure the cost of the initial 5 years of follow-up. It is true that many patients with lung cancer do not live for 5 years after treatment, but this assumption can be easily relaxed. The result would be a table of follow-up costs for every combination of TNM stage and projected years of survival. Indirect costs, such as time lost from work, transportation charges, and child or adult care charges, were not factored into this analysis. Similarly, treatment costs for new primary lung cancers, recurrences of the initial primary lung cancer, and other conditions detected during surveillance were ignored, although they may impose massive additional expenses for individual patients. Under these assumptions, the resulting cost estimates should be considered conservative and constitute baseline estimates of follow-up costs. All costs assumed away in this analysis would be considered add-ons to the estimates presented. Medicare-allowed charges were held constant at the 1992 level as charges were totaled over the 5 -year period for each of the eight strategies and compared across strategies. Total charges were converted to an actual charge proxy by a conversion ratio of 1.62 , which was calculated from actual submitted charges for 1992. ${ }^{44,45}$ Variation in charges across the eight separate follow-up strategies was then reanalyzed.

Follow-up charges were then calculated for each annual United States cohort of patients diagnosed with lung cancer. Rough estimates of charges per detected recurrence or second primary tumor were also calculated. It was conservatively assumed that $30 \%$ to $40 \%$ of all curatively treated patients with lung cancer would have a recurrence during the 5-year period after treatment and that annually $3 \%$ of all patients would develop a second primary cancer. For ease of calculation, no overlap was assumed between patients with recurrence and patients in whom a second primary tumor developed. Survival by year after treatment was estimated as follows: $39.0 \%$ at year 1 , $22.3 \%$ at year $2,17.3 \%$ at year $3,14.6 \%$ at year 4 , and $12.8 \%$ at year 5.47

\section{Results}

The strategy with the greatest frequency of any single test was that of Fischer ${ }^{38}$ with 22 office visits and 22 chest roentgenograms during 5 years of follow-up. The most intensive 5-year strategy across the greatest number of tests was that of Pairolero ${ }^{5}$ and Williams ${ }^{43}$ and their colleagues with 12 office visits, 12 blood tests, 12 chest roentgenograms, 12 sputum cytologic tests, and 12 urinalyses. Discounting the original Beattie ${ }^{41}$ strategy, which represented only 2 years of follow-up, the least intensive strategy was that of Walsh and colleagues, ${ }^{8}$ with six office visits and six chest roentgenograms.

The range of charges for follow-up of patients with lung cancer across strategies was wide. Medicare-allowed charges for 5 years of follow-up varied from a low of $\$ 946$ per patient on the basis of a strategy consisting of office visits and chest roentgenography to a high of $\$ 5645$ per patient on the basis of an intensive strategy consisting chiefly of office visits, CBCs, chest roentgenograms, bone scans, sputum cytologic tests, and CTs of the abdomen. When Medicare-allowed charges were converted to actual charges by a conversion ratio of 1.62 , the range was $\$ 1533$ to $\$ 9145$ per patient, a fivefold difference. This difference was not supported by any data demonstrating greater efficacy for the high-cost strategy.

Not surprisingly, those strategies that used frequent CT and bronchoscopy during the 5-year period were at the high end of the cost distribution. 
Those regimens that consisted mainly of some combination of office visits, chest roentgenograms, blood tests, and sputum cytologic tests were the least expensive. The lowest cost approaches consist of only one or two types of tests. Chest roentgenography and office visits were key components of all the strategies analyzed.

The charge figures quoted here can be considered conservative in today's economy inasmuch as they were derived from 1992 data. Updating these figures to 1995 levels can easily be accomplished by the use of the medical care component of the Consumer Price Index. Since 1960, this component has never been negative. ${ }^{48}$ The medical care component increased $5.94 \%$ in 1993 and $4.76 \%$ in 1994. A 10-year (1984 to 1994) average increase in the medical care component of $7.02 \%$ was used as an estimated increase for 1995. The result was a conservative estimate of the range of actual charges for 1995 across the follow-up strategies reviewed here of approximately $\$ 1820$ to $\$ 10,861$ per patient. This yields a difference of $\$ 9041$ per patient between the most intensive and least intensive follow-up strategies, compared with the original $\$ 4699$ (an increase of $\$ 4342$ or $48 \%$ per patient over 3 years).

Returning to the 1992 unadjusted data, for each annual cohort of patients curatively treated for lung cancer, the total 5-year follow-up charges (using the actual charge proxy) ranged from $\$ 7.8$ million to $\$ 164.9$ million depending on the intensity of followup. Averaged over the 11,219 to 14,599 recurrences or second primary tumors detected during the 5-year follow-up period for each annual cohort, the estimated charge per detected recurrence or second primary tumor ranged from $\$ 534$ to $\$ 695$ for nonintensive follow-up and from $\$ 11,295$ to $\$ 14,698$ for intensive follow-up.

\section{Discussion}

Few attempts have been made to measure the relevant costs associated with many medical practices, and the follow-up of patients with lung cancer is no exception. As this analysis has indicated, charges for follow-up can vary by as much as fivefold. Though the range of charges for follow-up of patients with lung cancer is not as wide as in the case of follow-up of patients with colon cancer, ${ }^{1}$ variation of even this magnitude cannot easily be justified in this era of cost containment and health care reform. The problem is an especially interesting one because little is known about how outcomes vary when the follow-up strategy is altered, and the optimal fol- low-up testing interval has never been defined by well-designed trials. No one strategy has been established as more efficacious than any other in terms of survival and quality of life, yet the surveillance of patients with lung cancer has achieved a greater degree of consensus than that for patients with colorectal cancer.

The most persuasive form of evidence would come from multisite prospective randomized controlled trials that tested the benefits of the various regimens advocated. Such trials have been reported for postoperative surveillance for breast cancer. ${ }^{49,50}$ Cost analyses of postoperative lung cancer surveillance are also lacking. Ideally, such analyses would incorporate not only the direct costs of follow-up, but also the indirect costs such as time lost from work, transportation costs, and child and adult care costs. Quality-of-life data should also be examined because such data are practically nonexistent in this field. ${ }^{51}$ Although recent nondefinitive retrospective data suggest that choice of treatment may be unaffected by follow-up, ${ }^{8,39}$ quality of life may be either directly or indirectly affected by the intensity of the follow-up regimen.

After a review of the literature regarding follow-up management practices for patients with a diagnosis of lung cancer, there are obvious questions that arise. Until prospective trials can be conducted, how should physicians choose among the recommended follow-up strategies in the literature in the absence of benefit data? Is there one follow-up strategy that should be applied to the majority of patients until further research can be conducted? In general, we recommend a minimalist strategy, such as that of Walsh and colleagues, ${ }^{8}$ which consists of an office visit and chest roentgenography every 6 months in year 1 and annually thereafter. This strategy is recommended because more intensive diagnostic testing has yet to demonstrate survival and quality-of-life benefits, although the cases of select patients might merit more intensive followup. At each visit, patients should be questioned about the presence of new symptoms or signs indicative of recurrence such as weight loss, difficulty breathing, bony pain, and headaches. The ordering of further tests would be based on this clinical evidence.

One limitation of the current analysis is that actual patients with lung cancer were not followed up prospectively to estimate costs. Though several strategies included in the analysis are based on actual patient data, a large prospective study would 
allow one to collect data on the costs of many factors assumed away in this analysis, such as diagnosis and treatment costs for patients with symptoms or positive test results.

A second limitation is that this study examines only follow-up after resection. Four times the number of curatively treated patients, or 140,000 patients, are treated nonoperatively each year. Such patients undergoing chemotherapy or radiation therapy are often followed up intensively after therapy. The cost ramifications of current follow-up practice for this large patient population may be even greater than for curatively treated patients with much less potential for improving survival.

Even the moderate cost differentials among surveillance strategies identified in this study will be increasingly difficult to sustain in the current competitive medical practice environment in which cost containment is such a dominant force. Though the variation in costs is moderate, the number of patients with lung cancer is large and, therefore, the total costs are staggering. Future research in the form of clinical trials is clearly needed to compare intensities of follow-up and to determine whether higher costs are substantiated by improved quality of life and longer survival.

\section{REFERENCES}

1. Virgo KS, Vernava AM, Longo WE, McKirgan LW, Johnson FE. Cost of patient follow-up after potentially curative colorectal cancer treatment. JAMA 1995;273:1837-41.

2. Menck HR, Garfinkel L, Dodd GD. Preliminary report of the National Cancer Database. CA Cancer J Clin 1991;41:7-18.

3. Wingo PA, Tong T, Bolden S. Cancer statistics 1995. CA Cancer J Clin 1995;45:8-30.

4. Immerman SC, Vanecko RM, Fry WA, Head LR, Shields TW. Site of recurrence in patients with stage I and II carcinoma of the lung resected for cure. Ann Thorac Surg 1981;32:23-7.

5. Pairolero PC, Williams DE, Bergstralh EJ, Piehler JM, Bernatz PE, Payne WS. Postsurgical stage I bronchogenic carcinoma: morbid implications of recurrent disease. Ann Thorac Surg 1984;38:331-8.

6. Iascone $\mathrm{C}$, DeMeester TR, Albertucci M, Little AG, Golomb HM. Local recurrence of resectable non-small cell carcinoma of the lung. Cancer 1986;57:471-6.

7. Lung Cancer Study Group. Malignant disease appearing late after operation for T1 N0 non-small-cell lung cancer. J Thorac Cardiovasc Surg 1993;106:1053-8.

8. Walsh GL, O'Connor M, Willis KM, et al. Is follow-up of lung cancer patients following resection medically indicated and cost effective? Ann Thorac Surg. In press.

9. Shields TW, Humphrey EW, Higgins GA, Keehn RJ. Longterm survivors after resection of lung carcinoma. $J$ Thorac Cardiovasc Surg 1978;76:439-45.

10. Rosengart TK, Martini N, Ghosn P, Burt M. Multiple primary lung carcinomas: prognosis and treatment. Ann Thorac Surg 1991;25:773-9.

11. Frost JK, Ball WC Jr, Levin ML, et al. Final report: lung cancer control, detection and therapy, phase II. Washington, D.C.: National Cancer Institute, 1984 (NCI publication no. [PHS] N01-CN-45037).

12. Flehinger BJ, Melamed MR, Zaman MB, Heelan RT, Perchick WB, Martini N. Early lung cancer detection: results of the initial (prevalence) radiologic and cytologic screening in the Memorial Sloan-Kettering study. Am Rev Respir Dis 1984;130:555-60.

13. Melamed MR, Flehinger BJ, Zaman MB, Heelan RT, Perchick WA, Martini N. Screening for early lung cancerr: results of the Memorial Sloan-Kettering study in New York. Chest 1984;86:44-53.

14. Romney BM, Austin JHM. Plain film evaluation of carcinoma of the lung. Semin Roentgenol 1990;25:45-63.

15. Venuta F, Rendina EA, Ciriaco P, et al. Computed tomography for preoperative assessment of $\mathrm{T} 3$ and $\mathrm{T} 4$ bronchogenic carcinoma. Eur J Cardiothorac Surg 1992;6:238-41.

16. Mori K, Yokoi K, Saito Y, Tominaga K, Miyazawa N. Diagnosis of mediastinal lymph node metastases in lung cancer. Jpn J Clin Oncol 1992;22:35-40.

17. Kono M, Adachi S, Kusumoto M, Sakai E. Clinical utility of Gd-DTPA-enhanced magnetic resonance imaging in lung cancer. J Thorac Imaging 1993;8:18-26.

18. Webb WR, Gatsonis C, Zerhouni EA, et al. CT and MR imaging in staging non-small cell bronchogenic carcinoma: report of the Radiologic Diagnostic Oncology Group. Radiology 1991;178:705-13.

19. Webb WR, Jensen BG, Sollitto R, et al. Bronchogenic carcinoma: staging with MR compared with staging with $C T$ and surgery. Radiology 1985;156:117-24.

20. Naunheim KS, Virgo KS, Coplin MA, Johnson FE. Clinical surveillance testing after lung cancer surgery. Ann Thorac Surg. In press.

21. Sze G, Shin J, Krol G, Johnson C, Liu D, Deck MDF. Intraparenchymal brain metastases: MR imaging versus contrast-enhanced CT. Radiology 1988;168:187-94.

22. Taphoorn MJB, Heimans JJ, Kaiser MCRLE, De Slegte RGM, Crezee FC, Valk J. Imaging of brain metastases: comparison of computerized tomography (CT) and magnetic resonance imaging (MRI). Neuroradiology 1989;31:391-5.

23. Duhaylongsod FG, Lowe VJ, Patz EF, Vaughn AL, Coleman RE, Wolfe WG. Detection of primary and recurrent lung cancer by means of F-18 fluorodeoxyglucose positron emission tomography (FDG PET). J Thorac Cardiovasc Surg 1995;110:130-40.

24. Hatfield MK, MacMahon H, Ryan JW, et al. Postoperative recurrence of lung cancer: detection by whole-body gallium scintigraphy. AJR Am J Roentgenol 1986;147:911-5.

25. Tockman MS, Erozan YS, Gupta P, et al. The early detection of second primary lung cancers by sputum immunostaining. Chest 1994;106:385S-90S.

26. Tockman MS, Gupta PK, Myers JD, et al. Sensitive and specific monoclonal antibody recognition of human lung cancer antigen on preserved sputum cells: a new approach to early lung cancer detection. J Clin Oncol 1988;6:1685-93.

27. Mulshine JL, Cuttitta F, Bibro M, et al. Monoclonal antibodies that distinguish non-small cell from small cell lung cancer. J Immunol 1983;131:497-502.

28. Rosen ST, Mulshine JL, Cuttitta F, et al. Analysis of human 
small cell lung cancer differentiation antigens using a panel of rat monoclonal antibodies. Cancer Res 1984;44:2052-61.

29. Ginsberg RJ. Follow-up supervision after resection for lung cancer. In: Delarue NC, Eschapasse $\mathrm{H}$, eds. International trends in general thoracic surgery. Vol. 1 (Lung cancer). Philadelphia: WB Saunders, 1985.

30. O'Neil KM, Lazarus AA. Hemoptysis: indications for bronchoscopy. Arch Intern Med 1991;151:171-4.

31. Poe RH, Levy PC, Israel RH, Ortiz CR, Kallay MC. Use of fiberoptic bronchoscopy in the diagnosis of bronchogenic carcinoma: a study in patients with idiopathic pleural effusions. Chest 1994;105:1663-7.

32. Popp W, Rauscher H, Ritschka L, Redtenbacher S, Zwick H, Dutz W. Diagnostic sensitivity of different techniques in the diagnosis of lung tumots with the flexible fiberoptic bronchoscope. Cancer 1991;67:72-5.

33. Sabiston DC, Spencer FC, eds. Surgery of the chest. 5th ed. Philadelphia: WB Saunders, 1990.

34. Baue AE, Geha AS, Hammond GL, Laks H, Naunheim KS, eds. Glenn's thoracic and cardiovascular surgery. 5th ed. Norwalk: Appleton \& Lange, 1991.

35. Roth JA, Ruckdeschel JC, Weisenburger TH, eds. Thoracic oncology. 1st ed. Philadelphia: WB Saunders, 1989.

36. Shields TW. Surgical treatment of non-small cell bronchial carcinoma. In: Shields TW, ed. General thoracic surgery. 4th ed. Baltimore: Williams \& Wilkins, 1994:1178.

37. Martini N, Ginsberg RJ. Postresection follow-up. In: Pearson FG, Deslauriers J, Ginsberg RJ, Hiebert CA, McKneally MF, eds. Thoracic surgery. New York: Churchill Livingstone, 1995.

38. Fischer DS. Follow-up of cancer: a handbook for physicians. 4th ed. Philadelphia: Lippincott-Raven, 1996. (Published under the auspices of the Connecticut State Medical Society, Connecticut Division of the American Cancer Society, Connecticut State Department of Health Services, Yale Cancer Center.)

39. Virgo KS, McKirgan LW, Caputo MCA, et al. Post-treatment management options for lung cancer patients. Ann Surg 1995;222:700-10.
40. Toporoff B, Morris PT. Thoracic carcinoma. In: Berger DH, Feig BW, Fuhrman GM, eds. The M.D. Anderson surgical oncology handbook. Boston: Little, Brown, 1995.

41. Beattie EJ. Lung cancer. In: Eiseman B, Robinson WA, Steele G Jr, eds. Follow-up of the cancer patient. New York: Thieme-Stratton, 1982.

42. Ginsberg RJ, Goldberg M, Waters PF. Surgery for non-small cell lung cancer. In: Roth JA, Ruckdeschel JC, Weisenburger TH, eds. Thoracic oncology. Philadelphia: WB Saunders, 1989.

43. Williams DE, Pairolero PC, Davis CS, et al. Survival of patients surgically treated for stage I lung cancer. J Thorac Cardiovasc Surg 1981;82:70-6:

44. Health Care Financing Administration. Part B Medicare Annual Data (BMAD) file, 1992a.

45. Health Care Financing Administration. Medicare Hospital Outpatient Bill (HOP) file, $1992 \mathrm{~b}$.

46. Johnson FE, Virgo KS, eds. Cancer patient follow-up. St. Louis: Mosby-Year Book. In preparation.

47. Miller BA, Ries LAG, Hankey BF, Kosary CL, Edwards BK, eds. Cancer statistics review: 1973-1989. Washington, D.C.: National Cancer Institute, 1992:I-25 (NIH publication no. 92-2789).

48. U.S. Bureau of Labor Statistics. Consumer Price Index, detailed report, multiple years. Washington: US Department of Labor.

49. GIVIO Investigators. Impact of follow-up testing on survival and health-related quality of life in breast cancer patients: a multicenter randomized controlled trial. JAMA 1994;271: 1587-92.

50. Del Turco MR, Palli D, Cariddi A, Ciatto S, Pacini P, Distante $\mathrm{V}$. Intensive diagnostic follow-up after treatment of primary breast cancer: a randomized trial. JAMA 1994;271: 1593-7.

51. Ladurie ML, Ranson-Bitker B. Quality of life following resection for lung cancer. In: Delarue NC, Eschapasse $\mathrm{H}$, eds. International trends in general thoracic surgery. Vol. 1 (Lung cancer). Philadelphia: WB Saunders, 1985. 